\title{
Long-term Effects of a Staff Development Programme on Effective Instruction and Classroom Management for Teachers in Multigrade Classes
}

\section{SIMON VEENMAN \& JAN RAEMAEKERS}

University of Nijmegen, Department of Educational Sciences, Psych. Lab. 4.27, P.O. Box 9104, 6500 HE Nijmegen, The Netherlands

SUMMARY This study describes the long-term effects of a staff development programme based on selected findings from teaching effectiveness research in schools with multigrade or mixed-age classes. The short-term effects of this programme were examined in two studies directed at schools with multigrade classes. The first improvement study was conducted in the school year 1986/87; the second improvement study was conducted in 1989/90. In the latter study, the effects of coaching in addition to participation in the staff development programme were also evaluated. In the school year 1992/93, a retention or follow-up study was conducted. A quasi-experimental, treatment-control group design was used to test the long-term effects of the programme 'Dealing with multigrade classes' and the effects of coaching. Based on pre- and post-training classroom observations, the follow-up study revealed a significant treatment effect for the time-on-task levels of the pupils in the multigrade classes and for the instructional and classroom management skills of the teachers. No significant differences were found between the coached and uncoached teachers and between the teachers who followed the programme either 2 or 5 years ago. No significant differences were found between the post-test and the retention test. This suggests that the training results were quite stable. No indication of further growth in the executive control of the selected instructional and classroom management skills was found. No significant differences in achievement were found between the pupils in classes with trained teachers and the pupils in classes with untrained teachers.

In this study the long-term effects of a school improvement programme directed at schools with multigrade classes are reported. In two previous improvement studies, we assessed the short-term effectiveness of the staff development programme for teachers in multigrade classes with respect to use of classroom time, instruction and classroom management. The training programme was inspired by the findings of our research into multigrade classes (Veenman et al., 1987). The design of the training programme was guided by research into 
effective staff development (Joyce \& Showers, 1988). The results of these two studies have been published in previous articles in Educational Studies (see Veenman et al., 1989; Roelofs et al., 1994). The purpose of the present study is to assess the effects of the staff development programme $2-5$ years after training.

\section{Background}

The major impact of demographic contraction and staffing cuts since the middle 1970 s on primary schools has been to increase the number of multigrade classes. Multigrade classes (also called mixed-age classes or combination classes) are classes in which students from two or more grades are taught by one teacher in one room at the same time. Students in multigrade classes retain their respective grade-level assignments and follow their grade-specific curricula. These classes are generally formed for administrative and economic reasons. Schools confronted with either decreases or increases in student enrolment, for example, are forced to redistribute the students within the prescribed student-teacher ratios. Small schools in sparsely populated areas have always had multigrade classes but the need for multigrade teaching is now being faced by a much wider group of schools both in rural and urban areas.

In the Netherlands, $53 \%$ of the primary school teachers have a multigrade class (Commissie Evaluatie Basisonderwijs, 1994). In a survey conducted in England and Wales, $40 \%$ of the schools surveyed reported an increase in multigrade grouping as a result of falling enrolments (Walsh et al., 1984). A further $15 \%$ reported that falling enrolments might lead to an increase in the extent of multigrade teaching in the future. Almost one-half of the new teachers in England and Wales had their first appointment in multigrade classes (Her Majesty's Inspectorate [HMI], 1982). One out of every seven classrooms in Canadian schools is a multigrade classroom consisting of two consecutive grades in one classroom. One out of every five students is enrolled in a multigrade classroom in Canada. In the urban districts of this large country, moreover, a greater number of multigrade classrooms are found than in the rural districts (Gayfer, 1991). The findings suggest that the multigrade classroom occupies a significant position in our schools today.

Multigrade teaching becomes a problem when it is forced upon the schools and the same groups cannot be maintained from year to year. Schools that are forced to set up multigrade classes make greater demands on their teachers in terms of classroom organisation and the creation of effective teaching-learning conditions for the pupils. Based on the results of three observational studies and interviews with a number of teachers in multigrade classes in the Netherlands, five problem areas have been identified: (1) the efficient use of instructional time, (2) the design of effective instruction, (3) classroom management, (4) the organisation of independent study, and (5) agreement upon the goals of multigrade teaching (Veenman et al., 1986).

To assist teachers in multigrade classes, a staff development programme was designed. This programme was centred around the problem areas identified 
above and incorporated selected findings from previous research on teacher and school effectiveness. In designing this programme, it was recognised that staff development or in-service activities often do not produce lasting effects (van Tulder, 1992) and special attention was therefore devoted to the transfer of training.

\section{Transfer of Training}

A considerable amount of time, energy and money is invested in staff development or in-service training today. Reviews of the literature on training, however, have indicated that little empirical attention has been devoted to the issue of training transfer (Baldwin \& Ford, 1988; Broad \& Newstrom, 1992). The instructional experiences provided by training are designed to develop new skills and new knowledge for application on the job. Transfer of training is defined as the degree to which the skills and knowledge acquired during training are effectively applied in the workplace. For transfer to occur, the trained behaviour must be generalised to the job context and maintained over a period of time. Full transfer also means that the level of the skill increases with on-the-job practice to beyond the level demonstrated at the end of the training programme.

Considering the low levels of transfer found for all types of training, Broad \& Newstrom (1992) have assumed that perhaps $50 \%$ of training content may still be applied 1 year after training. In order to promote conditions for transfer, Broad \& Newstrom propose the formation of transfer partnerships that include the trainees (i.e. learners), the trainers (i.e. designers and deliverers of the learning experiences), and the managers (i.e. leaders in the organisation with the authority and responsibility for the application of the learning on the job). Each partner has an important contribution to make to the transfer process, and full transfer requires that all of the partners co-operate to maximise the application of the new skills and knowledge on the job. Each partner can utilise a number of strategies before, during, and after training to enhance the transfer. Broad \& Newstrom (1992) developed an overview of the transfer strategies in the form of a matrix combining the time dimension (before-during-after training) with the role dimension (manager-trainer-trainee). Some of the strategies for managing transfer before training are, for example: collect baseline performance data, involve supervisors and trainees in needs analysis procedures (performed by the managers), systematic design instruction, involve managers and trainees (performed by the trainers), actively explore training options, and participate in advance activities (performed by the trainees). A number of the strategies identified by Broad \& Newstrom (1992) to facilitate the transfer of training have been incorporated into the design and execution of the staff development programme, 'Dealing with multigrade classes: a programme for school improvement' (Veenman et al., 1988). The following five topics have been considered in the programme: (1) instructional time, (2) effective instruction, (3) classroom management and organisation, (4) independent learning, and (5) school climate and school leadership. The content of the programme has been summarised in 
previous articles (see Veenman et al., 1989; Roelofs et al., 1994). Each chapter in the programme contained a rationale, a definition of terms, and specific guidelines for the implementation of the instructional behaviours in multigrade classes. To facilitate the understanding and use of the information in the programme, numerous case studies were provided, along with several checklists. Videotapes were also developed to demonstrate some of the behaviours involved in effective teaching and classroom management. In the second school improvement study, moreover, coaching was added to facilitate the transfer of the training.

\section{Coaching}

Research on training effects has shown a frequent failure to transfer the new knowledge and skills or, when initial transfer has been accomplished, rapid attrition of the newly acquired behaviours. Few studies have actually measured the transfer effects of training, but recent analyses show transfer only to occur when in-class coaching has been added to the initial training experience that includes theory, demonstration, practice and feedback (Bennett, 1987; Joyce \& Showers, 1988).

Coaching is defined by Joyce \& Showers (1980) as: 'Hands-on, in-classroom assistance with the transfer and application of skills to the classroom.' The process of coaching includes five major functions: (1) the provision of companionship, (2) the provision of technical feedback, (3) the analysis of application, (4) the adaptation to the students, and (5) personal facilitation. The first function is to provide interpersonal exchange with regard to a difficult process (i.e. the adoption of a new teaching strategy). This can result in mutual reflection, the checking of perceptions, the sharing of frustrations and successes, and thinking through mutual problems. The second function, the provision of technical feedback, helps ensure growth through practice in the classroom. Technical feedback includes pointing out omissions in the instructional strategy, examination of how the instructional materials are arranged, and checks for integration of the teaching strategy. The third function, the analysis of application, involves activities such as the selection of the appropriate occasions for the use of a newly acquired teaching strategy and examination of the existing curriculum for adequate use of the strategy. The fourth function, the adaptation to the students, involves learning how to teach the new strategy to the children. The fifth function, personal facilitation, refers to helping the teachers feel good about themselves during the early trials.

\section{Implementation of the Staff Development Programme}

In the first study directed at the evaluation of the short-term effectiveness of the staff development programme, the programme was conducted by members of the Department of Educational Sciences at the University of Nijmegen for teachers of grades one to six. In the school year 1986/87, the staff development 
programme was followed by 41 teachers from eight schools. From this group, 17 teachers were then selected for participation in the observational study (treatment group). Nine teachers from six schools in the same area were selected for observation but did not receive training (control group).

Based on the experiences of the teachers with the first version of the programme, the contents were slightly revised for the second version. The kindergarten teachers felt that too little attention was paid to kindergarten management and instruction. For this reason, an additional booklet was developed to deal with kindergarten instruction and classroom management. Coaching was also added to the training programme to enhance the transfer of training.

In the second study the staff development programme was conducted by teacher trainers and school counsellors in five locations in The Netherlands. Two months prior to the actual start of the training, the teacher trainers and school counsellors were trained by members of the Department of Educational Sciences to secure the same programme implementation as in the first study. In the school year 1989/90, the staff development programme was followed by 89 teachers of grades one to six from 12 schools. From this group, 28 teachers were then selected for participation in the observational study (treatment group). In addition to the training, 18 teachers from this treatment group also received in-class coaching. Fourteen teachers from six schools in the same areas were selected for study but did not receive training (control group).

In both of the short-term improvement studies, the contents of the training were the same. The kindergarten teachers in the second study received an additional booklet. Directly before and after training, the teachers who participated in the observational part of the short-term improvement studies were observed during two mathematics and two reading/language lessons. Following five to seven 3-hour workshops, the teachers in the multigrade classes implemented self-designed plans to increase specific teaching behaviours and pupil time on-task. Feedback was provided before the start of the first workshopbased on the results of pre-test observation, and after the last training sessionbased on the results of post-test observation. This feedback contained information about the time-on-task rates in the classes, the observed instruction and classroom management skills, and other aspects of the lessons. Between the workshops, the teachers were also asked to experiment with some of the teaching recommendations in their classrooms.

The design of the the training process was guided by the recommendations of Joyce \& Showers $(1980,1988)$. The five major components of training were: (1) presentation of theory; (2) modelling or demonstration; (3) practice; (4) structured feedback; and (5) coaching. The theory was presented in the handbook. Modelling or demonstration of the suggested teaching skills was done using video-fragments and the presentation of case-studies in the handbook. Practice under simulated conditions was achieved by role-playing with peers; practice under real conditions was achieved by asking the teachers to experiment with new ideas or improvement plans and report 
what they had done at the next workshop. As already mentioned, feedback was provided both before and after training.

Based on the pre- and post-training observations, the first improvement study revealed a significant treatment effect for the time-on-task levels of the pupils in the multigrade classrooms, effective instruction, and the classroom organisation and management behaviours of the teachers (Veenman et al., 1989). The second improvement study also revealed a significant treatment effect for the time-on-task levels of the pupils in the multigrade classes along with the instructional and classroom management skills of the teachers. Two coaching effects were found, namely for the effective organisation of instruction and for dealing with disturbances. The time-on-task levels improved more strongly in classes with coached teachers. The effects on the instructional and classroom management skills of the teachers and the on-task behaviour of the pupils in the second study were found to be smaller than those in the first study (Roelofs et al., 1994).

\section{Research Questions}

In the present study, the long-term effects of a staff development programme in school settings with multigrade classes are examined. The long-term effects of coaching in addition to the staff development programme are also evaluated. The research questions that guided the study were the following: Do teachers who followed the staff development programme in the school years 1986/87 and $1989 / 90$ still use the target behaviours after 2 and 5 years of training? Does the training appear to have a lasting effect on the time-on-task levels of the pupils? Are the effects of training greater for teachers who received coaching in addition to participation in the staff development programme? Does the training appear to have a positive effect on pupil achievement?

\section{Methods}

\section{Design}

The study was designed as a quasi-experiment with two treatment groups (uncoached teachers $(n=10)$ and coached teachers $(n=8)$ ) and one control group $(n=11)$. The classrooms in the retention study were selected from the first and second school improvement studies.

\section{Subjects}

The selection of the teachers for the first and second improvement studies is described in Veenman et al. (1989) and in Roelofs et al. (1994). In the following, the selection of the teachers for the retention study is described.

Of the 17 trained teachers who participated in the observational part of the first improvement study in the school year 1986/87, eight were willing to 
participate in the retention study 5 years later. Of the 10 trained but uncoached teachers who participated in the observational part of the second improvement study in the school year 1989/90, two were willing to participate in the retention study 2 years later. This produced a total of 10 trained but uncoached teachers for follow-up study. Of the 18 coached teachers in the second improvement study, eight were willing to participate in the retention study 2 years later. The total of 18 trained teachers (coached or uncoached) came from grades one to six in nine schools.

For the control group, 11 teachers were recruited from seven schools with socio-economic backgrounds and geographic locations comparable to those of the schools in the treatment group (six teachers from the nine control group teachers in the first improvement study and five teachers from the 14 control teachers in the second study).

In order to test for any self-selection effects among the teachers from the initial improvement studies, the instructional and classroom management pretest scores for the teachers who had volunteered for participation in the retention study were compared with the pre-test scores for the teachers who had not volunteered for participation. For the treatment groups $(n=18)$, no significant differences were found between the previously participating teachers and the newly recruited teachers. For the control group $(n=11)$, one significant difference was found. The newly-recruited control teachers were found to score significantly lower than the previously participating teachers on one of the five classroom management subscales, namely 'adjusting instruction to the needs of the pupils' $(p=<0.05)$. On the basis of these results, it was concluded that the degree of self-selection was minimal.

Although all of the teachers who participated in the observational part of the first and second improvement studies were asked to participate in the retention study, the number who volunteered was not very impressive (40\% for the treatment group and $57 \%$ for the control group). It should be noted that the schools and teachers were willing to participate in the first and second improvement studies as they received extensive training in return for their co-operation. Co-operation in a follow-up study $2-5$ years later, however, yielded no immediate profit for the schools and the teachers. This was the main reason for not participating in the retention study. Other reasons were: too busy, illness, and the teachers having left the school.

\section{Instrumentation}

The instruments used to measure the quantity and the quality of programme implementation and the time-on-task levels of the pupils were identical to those used in the first and second improvement studies. These included an observation instrument and a classroom rating-scale. Standardised achievement tests were also administered to measure pupil progress. 
Time on-task and instructional skills observation. Observational data on the timeon-task levels for the pupils were collected using a 'predominant activity' time-sampling procedure (Tyler, 1979). To obtain information on the behaviours of both the teachers and the pupils, a predetermined observational sequence was established. The observer examined the behaviour of the first pupil and that of the teacher for 7 seconds and then recorded this information in the next 13 seconds. After observation of all of the pupils, the observer started again with the first pupil.

An observation period lasted 40 minutes with optical and auditory signals (produced by an observation timer) to indicate the start of the observation period and the start of the coding intervals. The following four pieces of information were recorded for each observation period: (a) the response of the pupil to the task (e.g. on-task, off-task); (b) the target group of the teacher (e.g. grade level 5 or 6); (c) the task-related activities of the teacher (e.g. supervision, guided practice); and (d) the setting of the learning activities for each grade (e.g. group instruction, seatwork). The observation instrument, entitled COMMIT, included 20 categories. The most important observational variables used in the retention study are listed in Tables I and II. The observational data were collected using paper-and-pencil forms that could then be optically scanned.

Prior to the collection of the observational data, the three observers went through a training programme of about 40 hours. This involved the coding of videotapes as well as live coding. The training was conducted by an experienced trainer from the second improvement study who had been trained by an observer from the first improvement study to secure identical observational procedures and coding. The inter-observer reliability checks, estimated using analysis of variance (Winer, 1971), ranged from 0.70 to 1.00 (median 0.97 ) with the exception of one category: 'target group whole class'. The inter-observer reliability for this category was found to be 0.25 , which may be due to the fact that the teachers observed in the multigrade setting rarely directed their teaching to the entire class. All of the classrooms were observed by at least two different observers in order to minimise any observer effects.

Classroom rating scale. After each observation, the Management and Instruction Scale (MIS) was completed by the observer to assess teacher and pupil behaviours. The assessment consisted of five-point scales concerned with instructional skills, lesson design and execution, management of pupil behaviour, classroom organisation, and the level of disruptive or inappropriate behaviour.

The items in the MIS are based on the research of Evertson et al. (1983), Good et al. (1983) and Rosenshine \& Stevens (1986). The MIS contains 31 items and five subscales: (1) instructional skills, (2) organising instruction, (3) use of materials and space, (4) adjusting instruction and (5) dealing with disturbances. The alpha coefficients of the internal reliability of the different 


\begin{tabular}{|c|c|c|c|c|c|c|c|c|c|c|c|c|c|c|c|c|c|c|}
\hline \multirow[b]{4}{*}{ Variables } & \multicolumn{12}{|c|}{ Treatment group ( $n=18$ ) } & & & & & & \\
\hline & \multirow{2}{*}{\multicolumn{3}{|c|}{$\begin{array}{l}\text { Coached }(n=8) \\
1989 / 90(n=8)\end{array}$}} & \multicolumn{9}{|c|}{ Uncoached $(n=10)$} & & & & & & \\
\hline & & & & \multicolumn{3}{|c|}{$1986 / 87(n=8)$} & \multicolumn{3}{|c|}{$1989 / 90(n=2)$} & \multicolumn{3}{|c|}{ Total $(n=10)$} & \multicolumn{3}{|c|}{ Total $(n=18)$} & \multicolumn{3}{|c|}{ Control group $(n=11)$} \\
\hline & Pre & Post & Ret & Pre & Post & Ret & Pre & Post & Ret & Pre & Post & Ret & Pre & Post & Ret & Pre & Post & Ret \\
\hline \multirow{2}{*}{\multicolumn{19}{|c|}{$\begin{array}{l}\text { COMMIT } \\
\text { Pupil behaviour }\end{array}$}} \\
\hline & & & & & & & & & & & & & & & & & & \\
\hline On-task & 28.1 & 30.8 & 32.6 & 28.0 & 33.0 & 31.3 & 29.4 & 31.2 & 33.9 & 28.3 & 32.7 & 31.8 & 28.2 & 31.9 & 32.1 & 28.7 & 27.3 & 30.1 \\
\hline Procedural & 2.8 & 2.3 & 2.5 & 5.0 & 3.3 & 2.8 & 2.7 & 2.2 & 2.3 & 4.5 & 3.1 & 2.7 & 3.8 & 2.7 & 2.6 & 3.4 & 3.7 & 2.7 \\
\hline Waiting & 2.1 & 1.3 & 0.8 & 1.0 & 0.4 & 0.9 & 1.7 & 1.5 & 0.3 & 1.1 & 0.6 & 0.8 & 1.6 & 0.9 & 0.8 & 1.4 & 1.4 & 1.1 \\
\hline Not engaged & 7.0 & 5.6 & 4.2 & 6.0 & 3.3 & 5.1 & 6.3 & 5.1 & 3.5 & 6.1 & 3.7 & 4.8 & 6.5 & 4.5 & 4.5 & 6.6 & 7.5 & 6.1 \\
\hline \multicolumn{19}{|l|}{ Setting and on-task } \\
\hline \multicolumn{19}{|l|}{ Instruction } \\
\hline $\begin{array}{l}\text { and on-task (\%) } \\
\text { Seatwork }\end{array}$ & 71.8 & 81.6 & 86.0 & 76.7 & 86.6 & 89.4 & 77.2 & 823 & 90.1 & 76.8 & 85.7 & 89.6 & 74.6 & 83.9 & 88.0 & 75.4 & 72.7 & 81.8 \\
\hline and on-task $(\%)$ & 69.6 & 75.4 & 77.9 & 68.3 & 81.4 & 75.6 & 70.8 & 76.0 & 78.8 & 68.8 & 80.3 & 76.2 & 69.2 & 78.1 & 77.0 & 69.6 & 63.5 & 69.5 \\
\hline \multicolumn{19}{|l|}{ Teacher behaviour } \\
\hline \multicolumn{19}{|l|}{ Review of previous } \\
\hline Guided practice & 0.9 & 1.0 & 0.0 & 2.9 & 6.3 & 0.4 & 0.0 & 08 & 1.6 & 2.3 & 5.2 & 0.6 & 1.7 & 3.3 & 0.4 & 2.0 & 0.9 & 0.9 \\
\hline Monitoring & 5.8 & 4.6 & 4.3 & 4.0 & 3.9 & 3.4 & 5.1 & 5.7 & 0.9 & 4.2 & 4.3 & 2.9 & 4.9 & 4.4 & 3.5 & 3.2 & 4.0 & 3.0 \\
\hline Transitions & 5.8 & 5.6 & 4.0 & 6.0 & 5.4 & 3.6 & 4.3 & 3.8 & 1.3 & 5.6 & 5.1 & 3.1 & 5.7 & 5.3 & 3.5 & 4.6 & 5.5 & 3.6 \\
\hline \multicolumn{19}{|l|}{ No teaching } \\
\hline behaviour & 1.3 & 1.0 & 1.2 & 3.0 & 1.1 & 2.2 & 1.0 & 1.5 & 0.2 & 2.6 & 1.2 & 1.8 & 2.0 & 1.1 & 1.5 & 2.2 & 3.3 & 1.8 \\
\hline \multicolumn{19}{|l|}{ Subscales MIS } \\
\hline Instructional skills & 22.4 & 25.1 & 27.5 & 24.3 & 29.0 & 25.4 & 21.0 & 25.0 & 30.3 & 23.7 & 28.2 & 26.4 & 23.1 & 26.8 & 26.9 & 22.8 & 22.0 & 23.6 \\
\hline $\begin{array}{l}\text { Organising instruction } \\
\text { Use of materials }\end{array}$ & \multicolumn{2}{|c|}{ Use of materials } & 22.4 & 16.8 & 20.7 & 20.9 & 18.4 & 20.8 & 22.5 & 17.1 & 20.7 & 21.2 & 17.3 & 20.6 & 21.7 & 17.8 & 18.0 & 18.7 \\
\hline $\begin{array}{l}\text { Use of materials } \\
\text { and space }\end{array}$ & 24.6 & 27.5 & 28.8 & 21.1 & 25.2 & 26.4 & 25.5 & 26.3 & 29.5 & 22.0 & 25.4 & 27.0 & 23.2 & 26.3 & 27.8 & 24.0 & 24.6 & 27.8 \\
\hline Adjusting instruction & 21.4 & 24.1 & 26.3 & 20.7 & 24.4 & 24.8 & 22.0 & 24.3 & 26.5 & 21.0 & 24.4 & 25.2 & 21.2 & 24.3 & 25.7 & 21.5 & 21.3 & 23.4 \\
\hline disturbances & 20.4 & 24.2 & 26.3 & 19.7 & 24.6 & 23.1 & 20.1 & 24.6 & 27.5 & 19.8 & 24.6 & 24.0 & 20.1 & 24.4 & 25.0 & 19.8 & 20.2 & 22.0 \\
\hline
\end{tabular}

Note: Mean frequencies of pupil and teacher behaviour are expressed in minutes (lesson period $=40$ minutes). Ret $=$ retention test. 
TABLE II. Training and retention effects: results of $t$-tests on adjusted mean scores of observation categories of the COMMIT and subscales of the MIS of the retention study (pre-test scores used as covariates)

\begin{tabular}{|c|c|c|c|c|c|c|}
\hline & \multicolumn{3}{|c|}{ Training effects } & \multicolumn{3}{|c|}{ Retention effects } \\
\hline & $\begin{array}{l}\text { Training: } \\
\text { exp. } \\
\text { vs } \\
\text { con. }\end{array}$ & $\begin{array}{l}\text { Coaching: } \\
\text { coached } \\
\text { vs } \\
\text { uncoached }\end{array}$ & $\begin{array}{c}\text { Time: } \\
1986 / 87 \\
\text { vs } \\
1989 / 90\end{array}$ & $\begin{array}{l}\text { Training: } \\
\text { exp. } \\
\text { vs } \\
\text { con. }\end{array}$ & $\begin{array}{l}\text { Coaching: } \\
\text { coached } \\
\text { vs } \\
\text { uncoached }\end{array}$ & $\begin{array}{c}\text { Time: } \\
1986 / 87 \\
\text { vs } \\
1989 / 90\end{array}$ \\
\hline Observation categories & $t$ & $t$ & $t$ & $t$ & $t$ & $t$ \\
\hline \multicolumn{7}{|l|}{ COMMIT } \\
\hline \multicolumn{7}{|l|}{ Pupil behaviour } \\
\hline On-task & $3.83^{\star \star}$ & -0.28 & -0.19 & -1.29 & 0.69 & -1.60 \\
\hline Procedural & -1.69 & 0.24 & -0.10 & 1.15 & 0.38 & -0.32 \\
\hline Waiting & $-2.19^{\star}$ & -0.20 & 0.12 & -0.11 & -0.31 & $2.08^{\star}$ \\
\hline Not engaged & $-3.14^{\star \star}$ & 0.26 & -0.01 & 1.07 & -1.19 & 1.84 \\
\hline \multicolumn{7}{|l|}{ Setting and on-task } \\
\hline $\begin{array}{l}\text { Instruction } \\
\text { and on-task (\%) }\end{array}$ & $3.44^{\star \star}$ & -0.36 & 0.41 & -0.80 & -0.14 & -0.52 \\
\hline $\begin{array}{l}\text { Seatwork } \\
\text { and on-task (\%) }\end{array}$ & $3.86^{\star \star}$ & -0.37 & 0.39 & -1.97 & 1.02 & -1.44 \\
\hline \multicolumn{7}{|l|}{ Teacher behaviour } \\
\hline Review of previous work & $4.93^{\star \star}$ & 1.78 & -2.05 & -0.26 & 1.65 & -0.60 \\
\hline Guided practice & 1.56 & -1.75 & 0.68 & -1.47 & 0.91 & $-2.56^{\star}$ \\
\hline Monitoring & -0.25 & 0.54 & 0.43 & -0.45 & 0.96 & 1.22 \\
\hline Transitions & -1.52 & 1.11 & 0.89 & -0.09 & 0.37 & 0.27 \\
\hline No teaching behaviour & $-2.59^{\star}$ & 0.27 & -0.09 & 1.52 & 0.29 & 1.28 \\
\hline \multicolumn{7}{|l|}{ Subscales MIS } \\
\hline $\begin{array}{l}\text { Instructional skills } \\
\qquad(\alpha=0.90)\end{array}$ & $4.89^{\star \star}$ & -0.88 & -0.87 & -0.27 & 1.04 & $-3.75^{\star \star}$ \\
\hline $\begin{array}{l}\text { Organising instruction } \\
\quad(\alpha=0.84)\end{array}$ & $4.10^{\star \star}$ & 0.22 & -0.03 & 0.56 & 0.73 & -0.71 \\
\hline $\begin{array}{l}\text { Use of materials and } \\
\text { space }(\alpha=0.66)\end{array}$ & 1.95 & 1.00 & -0.24 & -0.83 & -0.46 & -0.62 \\
\hline $\begin{array}{l}\text { Adjusting instruction } \\
\quad(\alpha=0.86) \\
\text { Dealing with }\end{array}$ & $3.37^{\star \star}$ & 0.24 & -0.22 & -0.48 & 0.69 & -0.91 \\
\hline disturbances $(\alpha=0.91)$ & $3.12^{\star \star}$ & 0.09 & -0.90 & -0.51 & 0.78 & -1.62 \\
\hline
\end{tabular}

Note: Exp. $=$ experimental (treatment) group; con. $=$ control group. Time $=$ application time. $\star=p<0.05 ;{ }^{\star \star}=p<0.01$.

subscales ranged from 0.81 to 0.91 (see Table I). The inter-observer reliability checks for all of the subscale scores, estimated using analysis of variance, ranged from 0.63 to 0.81 (median 0.74 ). 
Achievement tests. Three standardised achievement tests were used to measure pupil progress: one for decoding or technical reading (Brus-Voeten Test), one for reading comprehension (CITO and Aarnoutse Test) and one for mathematical skills (De Vos Test). These tests were administered in the classes with trained and the classes with untrained teachers (grades one to six) to determine the effects of the staff development programme on pupil achievement. The technical reading and mathematical tests were suitable for all of the grades involved. For reading comprehension, different tests that nevertheless measured the same construct were used for each grade.

\section{Data Collection}

For the first improvement study, the pre-test took place in November-December 1986 and the post-test in May-June 1987. For the second improvement study, the pre-test was administered in November-December 1989 and the post-test in May-June 1990. The follow-up test was administered during the period May-July 1992, 5 years after the post-test in the first improvement study and 2 years after the post-test in the second improvement study.

Each teacher in the retention study was observed for one mathematics and one reading/language lesson. All of the observations took place in the morning. The observational data of the COMMIT were then expressed in minutes. The teacher and pupil behaviours within each category were averaged for each class and each teacher, and the observations for a particular subject (mathematics and reading/language) were then averaged to produce the mean rates for each observation period (i.e. the retention data). It was recognised that the observational variables were not independent of each other and that the coding of an event into one category excludes it from inclusion in all of the other categories for that interval. Subscale scores for the MIS were computed by adding the values of the responses for each subscale together.

In testing for differences between the treatment teachers and the control teachers, a significance level of $5 \%$ was used (one-tailed). The class or teacher was the unit of analysis for the observational data. The pupil was the unit of analysis for the achievement data. For a more detailed description of the design, instrumentation, and data collection in this study, see Raemaekers \& Veenman (1994).

\section{Results}

To determine the effects of the staff development programme, an analysis of covariance (ANCOVA) with the pre-test as a covariate was undertaken. The post-test and retention scores constituted the dependent variables, with treat- 
ment (training or no training) as an independent variable. Three comparisons were made: (1) the control group versus the treatment group; (2) coaching versus no coaching; and (3) the treatment group from 1986/87 versus the treatment group from 1989/90. It should be noted that only the teachers who did not receive coaching in the second improvement study could be used for comparison to the teachers in the first improvement study (which did not include coaching).

When comparing the treatment group (i.e. trained teachers either with or without coaching) with the control group to test for initial differences, no significant differences were found. The treatment groups with and without coaching differed at pre-test for the observational category of 'procedural activities'. The pupils in the classes with trained teachers who also received coaching spent less time on procedural activities than pupils in the classes with trained teachers who did not receive coaching $(p<0.05)$. In addition, the coached teachers were rated significantly higher than the non-coached teachers on one of the subscales of the MIS: 'use of materials and space' $(p<0.05)$. In sum, no significant differences were found between the control group and the treatment groups prior to training. Minor differences were found between the two treatment groups (i.e. the coached versus uncoached teachers).

\section{Training Effects}

A summary of the descriptive statistics for each independent variable on the COMMIT and MIS is presented in Table I. In Table II, the results of the statistical tests are summarised. In the columns regarding the 'training effects' of the staff development programme, representing the differences between the treatment and the control groups and the treatment groups themselves, the post- and retention-test scores have been averaged to produce a combined score. This score is then compared for the experimental versus control groups and the different treatment groups with the pre-test score as a covariate. The results of the significance tests are expressed as $t$-values (expressing the differences between two contrasting groups), and the information found in Table I should be kept in mind when interpreting these results.

Effects of the training programme. A comparison of the mean scores for the treatment group (coached and uncoached teachers) with the mean scores for the control group showed the staff development programme to have a significant effect on the time-on-task rates for the pupils. The treatment group pupils exhibited higher time-on-task levels than the control group pupils: $80 \%(32.0$ minutes) versus $72 \%$ ( 28.7 minutes), which proved to be statistically significant $(p<0.01)$. The treatment group pupils spent significantly less time waiting for the teacher and were more engaged in their work than the control group pupils.

Table II also presents the outcomes regarding the amount of time on-task during class instruction and individual seatwork. The treatment group pupils 
were in both settings significantly more on-task than the control group pupils. During class instruction, the treatment group pupils were found to spend $86 \%$ of the observation time on their learning tasks (34.4 minutes), and during individual seatwork $78 \%$ of the observation time ( 31.0 minutes). The respective figures for the control group pupils were $77 \%$ (30.9 minutes) and 66\% (26.6 minutes). These results indicate that the trained teachers were able to establish classes with a greater proportion of the pupils engaged in learning tasks (on-task) than in the control classes.

In Table II, information regarding some of the teacher behaviours is summarised to estimate the degree of programme implementation. Significant differences between the treatment and control teachers were found for the variables 'review of previous work' and 'no teaching behaviour'. The treatment teachers spent significantly more time than the control teachers on behaviours intended to activate pupils' prior knowledge of the subject matter and significantly less time than the control teachers on organisation of the classroom ( $5 \%$ versus $3 \%$ and $1 \%$ versus $6 \%$ ).

Finally, the results for the MIS are also summarised in Table II. The results show those teachers who participated in the training to attain substantially higher scores than the control teachers. Significant implementation effects were found for four of the five subscales. No treatment effect was found for the subscale 'use of materials and space'. In general, the trained teachers were found to use more effective instructional, classroom management and organisational techniques than the control teachers. The trained teachers improved markedly on instructional skills, the organisation of instruction, the adjustment of the instruction to pupil abilities and dealing with disturbances.

Effects of coaching. No significant differences were found between the coached and uncoached teachers. Coaching had no lasting effect on time-on-task levels of the pupils or the instructional and classroom management skills of the trained teachers.

Effects of application time. It was expected that the teachers who had participated in the training 5 years previously would show higher implemention rates than the teachers who had participated in the training just 2 years ago. The findings in the column 'training effects' in Table II reflect the influence of treatment in $1986 / 87$ versus $1989 / 90$. No significant differences were found between these two groups. It should be noted, however, that the 1989/90 treatment group represents the scores of only two teachers. The results of this test should, therefore, be interpreted with caution.

\section{Retention Effects}

In order to examine the retention effects of the staff development programme, the differences between the retention scores and the post-test scores (expressed 
as gain scores) were compared for the experimental (coached and uncoached teachers) versus control groups and the different treatment groups with the pre-test score as a covariate. The outcomes of these comparisons are grouped under the heading 'retention effects' in Table II.

Effects of the training programme on retention. When the pre-test scores were controlled for, no significant difference was found between the treatment and control groups. One may conclude that the treatment teachers did not show an increase between the post-test and the retention test in the application of the desired instructional and classroom management skills. No indication of further growth in the 'executive control' of these skills was found. In other words, it was difficult to improve upon the results achieved directly after training.

Effects of coaching on retention. No significant differences were found between the uncoached and coached teachers. In spite of the additional support and classroom assistance, the coached teachers did not gain more between the post and retention tests than the uncoached teachers.

Effects of application time on retention. Three significant differences were found between the 1989/90 treatment teachers and 1986/87 treatment teachers. Although no significant differences were found in the time-on-task levels for the pupils in these two groups, the $1989 / 90$ group showed a significant decrease in the off-task behaviour of 'waiting' $(p<0.05)$ when compared to the $1986 / 87$ group. The 1989/90 treatment teachers also showed larger gains for 'guided practice' $(p<0.05)$ and the 'instructional skills' subscale of the MIS $(p<0.01)$ when compared to the $1986 / 87$ group. Unexpectedly, the $1989 / 90$ treatment teachers gained more on these variables between the post and retention test than the 1986/87 treatment teachers. Considering the number of dependent variables, however, the differences between the two treatment groups appear to be minimal.

\section{Pupil Achievement}

Table III summarises the long-term effects of the staff development programme on pupil achievement. It should be noted that the number of teachers who participated in the pupil achievement part of the retention study is larger than the number of teachers who participated in the observational part of the retention study. All of the teachers did not agree to open their classes for follow-up observations. Of the 12 classes in the follow-up treatment group with uncoached teachers, seven of the teachers had participated in the first improvement study and five in the second improvement study. All of the classes in the follow-up treatment group with coached teachers $(n=14)$ had participated in the second improvement study (coaching was not applied in the first improve- 
TABLE III. Means, standard deviations (SD), and ANOVA test results for $z$-scores concerning achievement outcomes across grades

\begin{tabular}{|c|c|c|c|c|c|c|c|c|}
\hline \multirow[b]{2}{*}{ Subject area } & \multicolumn{3}{|c|}{ Treatment group } & \multicolumn{3}{|c|}{ Control group } & \multirow[b]{2}{*}{$F$} & \multirow[b]{2}{*}{$p$} \\
\hline & $n$ & Mean & SD & $n$ & Mean & $\mathrm{SD}$ & & \\
\hline Technical reading & 630 & 0.01 & 1.00 & 349 & -0.02 & 0.99 & 0.21 & 0.64 \\
\hline Reading comprehension & 634 & 0.04 & 1.01 & 329 & -0.07 & 0.97 & 2.63 & 0.11 \\
\hline Mathematics & 632 & -0.02 & 1.00 & 337 & 0.04 & 1.00 & 0.90 & 0.34 \\
\hline
\end{tabular}

Note: Treatment group: $n=26$ classes; control group: $n=14$ classes.

ment study). In the follow-up control group 14 teachers participated (seven from the first and seven from the second improvement study).

To account for the differences in the lengths of the reading comprehension and mathematics tests, all of the raw pupil scores were standardised per grade level using $z$-scores. Independent, one-tailed $t$-tests were then applied to test for any differences between the treatment and control groups, the coached and uncoached teachers, or the $1986 / 87$ and $1989 / 90$ treatment groups. No significant cross-grade achievement differences were found. The treatment classes did not perform better than the control classes. Systematic differences were also not found per grade level (see Raemaekers \& Veenman, 1994). Furthermore, no significant differences were found between the classes of the coached and uncoached teachers or between the classes of the teachers in the $1986 / 87$ treatment group and the classes of the teachers in ther 1989/90 treatment group. Note that the last comparison involved only uncoached teachers. These findings should also be treated with caution as pre-treatment achievement data were not available. This means that any initial differences in pupil achievement could not be controlled for.

\section{Discussion}

In two previous studies, the short-term effects of the staff development programme 'Dealing with multigrade classes' were assessed. The results of these studies showed important gains in instructional skills and the way in which the trained teachers organised instruction and adapted it to the pupils. Classroom management skills such as the use of materials/space, and dealing with disturbances also improved markedly for the trained teachers. The time-on-task levels for the pupils with trained teachers also increased substantially. Finally, coached teachers were found to differ from uncoached teachers on only two aspects of instruction and classroom management: organisation of the instruction and dealing with disturbances. For both aspects, the coached teachers showed larger gains than the uncoached teachers. 
In the present study, the long-term effects of the staff development programme were examined. Observational data collected 2 and 5 years after the conclusion of the training programme showed the trained teachers still demonstrated the target teaching behaviours. The group differences two and five years after training show the staff development programme to have enhanced the skills of teachers in multigrade classes. The target skills appear to have been transferred and sustained over time.

A number of transfer strategies were applied both before and during the training period. The teachers were briefed on the importance of the training objectives, content, process, and application for the teaching of multigrade classes. Both trainers and trainees were involved in the planning of the programme. The trainees were selected because of their desire to improve their instructional and classroom management skills for the teaching of multigrade classes. Baseline performance data were used during the training programme to formulate clear improvement plans. The training was systematically developed and based on the components of effective training outlined by Joyce \& Showers (1988). Joint expectations for improvement were established. Opportunities to practise newly acquired skills were provided in both simulated and real classroom settings. Realistic work-related tasks and cases were provided (situated cognition). A coaching component was added to the programme in order to facilitate the transfer of newly acquired skills to the classroom. Opportunities for the discussion of ideas and their applications were created. Case studies were used to illustrate how other teachers had implemented a particular teaching skill in a multigrade classroom. Trainees planned and then discussed their plans. The incorporation of strategies to facilitate the transfer of training (cf. Broad \& Newstrom, 1992) may have contributed to the lasting effects of the staff development programme.

One strategy for the promotion of transfer did not appear to be particularly successful, however. The coaching of teachers did not produce a lasting effect on the on-task levels of the pupils or the skills of the teachers. This finding may be explained by the way in which coaching was performed. The results of the second improvement study (see Roelofs et al., 1994) suggest that all of the coaching functions may not have been implemented effectively. The provision of support and technical feedback with regard to the newly acquired skills was found to be valued positively by the coached teachers. Little attention was paid to how the newly acquired skills should actually be applied in the classroom or adapted to the characteristics of the pupils. Joyce $\&$ Showers (1988) nevertheless argue that these last two functions are particularly important for the integration of the newly acquired behaviours into the daily teaching repertoire. In this respect, critical differences between the coaches were observed and a more structured set of guidelines for the coaching of teachers on the job may be needed.

No effects were found for the length of application. The teachers who had participated in the training 5 years ago showed no higher implemention rates than the teachers who had participated in the training 2 years ago. The 1989/90 
treatment group contained only two teachers, which suggests that the possibility of greater skill perfection over time should be evaluated in further research.

The full transfer of training in the present context means that the level of skill should increase beyond the level demonstrated at the end of the staff development programme. Such an increase was not found in the present study. When compared to control teachers, the treatment teachers did not show an increase over time in the application of the desired instructional and classroom management skills. Interviews with the teachers using the Levels of Use of the Innovation (LoU) (Hall \& Loucks, 1977; Hord et al., 1987) showed the trained teachers to be functioning at level 3, 'mechanical use', and level 4a, 'routine use' (see Raemaekers \& Veenman, 1994). A 'stable, routine' pattern of use appeared to have been established. This may be due to the fact that most of the instructional and classroom management skills were defined in very concrete teaching terms (e.g. review previous work, provide individualised help). Such concrete behavioural descriptions provide little room for further refinement or higher frequencies of application. Each lesson, for example, has only one moment that is appropriate for the review of previous work; teachers usually review the previous work at the beginning of a lesson. The provision of individualised help depends on the number of pupils in need of help. No teacher will deliberately create confusing situations in order to maximise the number of opportunities for individualised help.

It is interesting to note that although the trained teachers achieved higher time-on-task levels than the untrained teachers, these higher time-on-task levels did not result in higher pupil achievement. No significant achievement differences were found for the classes with trained versus untrained teachers. There are two potential explanations for why more time on-task was not associated with higher pupil achievement. First, the teachers may have treated time as a homogeneous entity. More time may simply have been taken to mean more of the same. No effort was made in this study to partition time into various pupil or teacher behaviours. We do not know, therefore, if more time was spent on the right tasks. Time was measured quantitatively and not qualitatively. In a revised edition of the staff development programme, the teachers should be trained to examine their time-on-task data in light of the question: time on what task? The quality of the task may determine just which and how much learning occurs. Second, the staff development programme was mainly directed at the improvement of teacher behaviours in multigrade classes. A stronger coupling between teacher and pupil behaviours may be needed. To improve pupil learning, teachers may need to be stimulated to identify the desired pupil behaviours and then the teacher behaviours needed to evoke such pupil behaviours. In such a way, the time-on-task levels of the pupils may become more directly related to their achievement.

Two to 5 years after training, the guided practice aspect of the staff development programme appears to have been wiped out. Guided practice is considered an important teaching skill in multigrade classes because it shows whether the pupils are prepared to start individual seatwork or not. If the 
pupils are not ready, errors and frustration may decrease their interest and their performance. In addition, the pupils in the first group may interrupt the teacher during the instruction of the second or third groups, which may produce confusion and thereby decrease pupil performance further. Only when pupils understand the new material and are largely able to work out the problems correctly can the teacher proceed to the instruction of other groups in a multigrade class. As the pre-test data suggest (see Table I), teachers often simply assume that their presentations have been understood. After their presentations, they switch directly to seatwork or the independent work portion of the lesson, and leave the instructed group without supervision to instruct a new group. Directly after training, the teachers in this study were found to use guided practice significantly but not impressively more than before training. Two or 5 years after training, however, this treatment effect disappeared. The teachers attempted to use the skill for a period of time, but its use quickly diminished to the level of the pre-training baseline. This decline may be due to a perceived lack of success with the skill, the constraints of the complex work environment associated with a multigrade class, a lack of support for the use of this particular skill, or a combination of these factors. In the future, greater attention should be paid to transfer strategies in the work environment of teachers in multigrade classes (e.g. follow-up support).

\section{Acknowledgements}

The research reported here was supported by a grant from the Institute for Educational Research in the Netherlands (SVO-project 1111). The authors gratefully acknowledge the following persons for their contributions to this study: Rinus Voeten, Cora van den Berg, Mirjam van Moorsel, Carla Motshagen, Desiree Jacobs, Nelleke Hofs, and the participating principals and teachers for their co-operation.

\section{REFERENCES}

BALDWIN, T.Y. \& FoRD, J.K. (1988) Transfer of training: a review and directions for future research, Personnel Psychology, 41, pp. 63-105.

BenNeTt, B. (1987) The effectiveness of staff development training practices: a meta-analysis, unpublished doctoral dissertation, University of Oregon.

BROAD, M.L. \& NewSTROM, J.W. (1992) Transfer of Training: action-packed strategies to ensure high payoff from training investments (Reading, Addison Wesley).

COMMISSIE EVALUATIE BASISONDERWIJS (1994) Inhoud en opbrengsten van het basisonderwijs (Contents and Results of Primary Education) (Leiden, Distributiecentrum DOP).

Evertson, C.M., EMmer, E.T., SANFord, J.P. \& Clements, B.S. (1983) Improving classroom management: an experiment in elementary school classrooms, Elementary School foumal, 84, pp. 173-188.

GAYFER, M. (1991) The Multi-grade Classroom: myth and reality. A Canadian study (Toronto, Canadian Education Association).

Good, T.L., Grouws, D.A. \& Ebmerer, H. (1983) Active Mathematics Teaching (New York, Longman). 
HALL, G.E. \& Loucks, S.F. (1977) A developmental model for determining whether the treatment is actually implemented, American Educational Research fournal, 14, pp. 263-276.

HER MAJESTY'S INSPECTORATE (1982) The New Teacher in School (London, HMSO).

Hord, S.M., RuTHERFord, W.L., HuLING-Austin, L. \& HALl, G.E. (1987) Taking Charge of Change (Alexandria, Association for Supervision and Curriculum Development).

JOYCE, B.R. \& SHOWERS, B. (1980) Improving inservice training: the messages of research, Educational Leadership, 37, pp. 379-385.

JoYce, B.R. \& SHOWERs, B. (1988) Student Achievement through Staff Development (New York, Longman).

RAEMAEKERS, J. \& VEENMAN, S. (1994) Institutionalisering van teamgerichte nascholing: Duurzame effecten van de cursus Omgaan met Combinatieklassen (Institutionalisation of a Staff-Development Programme: long-term effects of the programme Dealing with Multi-grade Classes) (Nijmegen, Instituut voor Toegepaste Sociale Wetenschappen).

Roelofs, E., Veenman, S. \& Raemaekers, J. (1994) Improving instruction and classroom behaviour in mixed-age classrooms: results of two improvement studies, Educational Studies, 20, pp. 105-126.

Rosenshine, B.V. \& Stevens, R. (1986) Teaching functions, in: M. C. WiTtrock (Ed.) Handbook of Research on Teaching, 3rd edn, pp. 376-391 (New York, Macmillan).

Tyler, S. (1979) Time-sampling: a matter of convention, Animal Behavior, 27, pp. 801-810.

VAN TULDER, M. (1992) Nascholing en onderwijsvernieuwing (In-service education and educational innovation), doctoral dissertation, University of Nijmegen.

Veenman, S., LEM, P. \& NiJSSEN, F. (1988) Omgaan met combinatieklassen: een programma voor schoolverbetering (Dealing with Mixed-Age Classes: a staff development programme for school improvement) ('s-Gravenhage, Instituut voor Onderzoek van het Onderwijs).

VeENMAN, S., LEM, P. \& RoELOFS, E. (1989) Training teachers in mixed-age classrooms: effects of a staff development programme, Educational Studies, 15, pp. 165-180.

Veenman, S., Lem, P., Voeten, M., Winkelmolen, B. \& Lassche, H. (1986) Onderwijs in combinatieklassen (Instruction in Multi-grade Classes) ('s-Gravenhage, Instituut voor Onderzoek van het Onderwijs).

Veenman, S., Voeten, M. \& Lem, P. (1987) Classroom time and achievement in mixed-age classes, Educational Studies, 13, pp. 75-89.

Walsh, K., Dunne, R., Stoten, B. \& Stewart, J.D. (1984) Falling School Rolls and the Management of the Teaching Profession (Windsor, NFER-Nelson).

WINER, B.J. (1971) Statistical Principles in Experimental Design (New York, McGraw-Hill). 